\title{
BIOFILM FORMATION AND ANTIBIOTIC RESISTANCE IN STAPHYLOCOCCUS ISOLATED FROM DIFFERENT OBJECTS
}

\author{
Yurii Vishovan ${ }^{1}$ \\ Valerii Ushkalov $\bowtie$ \\ Department of Epizootology Microbiology and Virology ${ }^{2}$ \\ ushkalov63@gmail.com \\ Lilia Vygovska \\ Liudmyla Ishchenko ${ }^{I}$ \\ Aidyn Salmanov \\ Research Laboratory \\ Scientific Research Laboratory of Shupik National Healthcare University of Ukraine \\ 9 Dorohozhytska str., Kyiv, Ukraine, 04112 \\ Andrii Bilan \\ Uman Labs \\ 3 Ivana Honty str., Uman, Ukraine, 20300 \\ Liubov Kalakailo \\ Department of molecular genetic research ${ }^{1}$
}

Andrii Hranat ${ }^{1}$

Serhii Boianovskiy ${ }^{l}$

${ }^{1}$ Ukrainian Laboratory of Quality and Safety of Agricultural Products ${ }^{2}$

${ }^{2}$ National University of Life and Environmental Sciences of Ukraine 15 Heroyiv Oborony str., Kyiv, Ukraine, 03041

$\triangle$ Corresponding author

\section{Abstract}

Staphylococci have a wide range of pathogenic properties, among which stands increased resistance to antibiotics and the ability to form a biofilm. Being divided into coagulase-positive and coagulase-negative, they have different and, at the same time, common biological properties and may be a source of genetic material for each other.

The aim of the study was to examine the properties of staphylococci, isolated from various objects (milk, pigs, companion animals, humans), their resistance to antibiotics, the ability to form a biofilm and the presence of genes, responsible for resistance to methicillin and biofilm formation.

In this study we used 89 Staphylococci strains. 18 (20.2\%) strains were coagulase-positive, where 2 (2.2\%) strains, isolated from different animals and humans, had a complete set of phenotypic (plasma coagulation, biofilm formation, resistance to oxacillin and benzylpenicillin) and genotypic (mec A, fem B, ica A, ica D) signs of pathogenicity.

Coagulase-negative staphylococci, isolated from various animals and humans, had resistance to oxacillin, benzylpenicillin and the ability to form biofilms, and also had the corresponding genes in their structure (mec A, ica AB, ica D) in $3.3 \%$ of cases.

Staphylococci, isolated from different animals and humans, were able to form a biofilm and had the appropriate set of genes (ica $\mathrm{D}$, ica $\mathrm{AB}$ ) in $5.6 \%$ of cases.

Keywords: biofilms, staphylococci, intercellular adhesion, antibiotic resistance, LA-MRS.

DOI: $10.21303 / 2504-5695.2021 .001925$ 


\section{Introduction}

For more than a hundred years microbiologists from different countries have been studying the biological properties of staphylococci to determine the factors that provide this pathogen the ability to reproduce in different biological niches and cause different diseases [1]. Staphylococci have a wide range of pathogenic properties that cause many diseases in all warm-blooded animals and humans. Also, staphylococci with their high pathogenic potential and virulence are the causative agents of secondary infections, complicating the main course of the disease $[2,3]$.

The two groups of staphylococci are being divided into coagulase-positive and coagulase-negative. They have different and, at the same time, common biological properties and may be a source of genetic material for each other $[4,5]$. As a result of in-depth study of antibiotic resistance of staphylococci, a separate group of $S$. aureus LA (livestock animals) - resistant (MRS) and sensitive (MSS) to methicillin was identified. This group includes isolates from farm animals (cattle, sheep, goats, poultry, pigs) and companion animals [2, 6, 7]. Resistance to methicillin in Staphylococcus aureus occurs due to acquisition of additional penicillin-binding protein, PBP2' (Also known as PBP2a), which confers resistance to virtually all $\beta$-lactam antibiotics $[8,9]$. The femB gene encodes an enzyme, important for the crosslinking of peptidoglycan in various different Staphylococcus spp. [10, 11]. Staphylococcal strains, containing antibiotic resistance genes, colonize the mucous membranes and skin of almost all entire spectrum of animal species and especially domesticated animals with the ability to transmit staphylococci to other animals and humans [7, 12]. In addition, among coagulase-positive and coagulase-negative staphylococci, isolated from different domestic and wild animals, there is a phenomenon of polyresistance to antibiotics of different groups [13-18].

Another important problem is the high level of registration of staphylococcal diseases among animals and humans. Thus, according to the US Centers for Disease Control and Prevention (CDC), in 2017, 323,700 cases of staphylococcal infections and about 10,600 deaths, caused by them, were registered in hospital patients. The estimated financial loss from it this year was in the range of 1.7 USD billion. [19]. At this time, the phenomena of biofilm formation, often in response to aggressive factors (detergents, disinfectants, antibiotics), need in-depth study. Staphylococci produce a basic biofilm exopolysaccharide called polysaccharide intercellular adhesive (PIA), or, in its chemical composition, poly-N-acetylglucosamine (PNAG) [20-23].

PIA biosynthesis is carried out by the products of the ica gene locus (intercellular adhesion), which includes the ica A, icaD, icaB and icaC genes [20-23].

The ica cluster, icaADB andC, encodes enzymes that mediate cell adhesion and synthesis of PIA, which is important for biofilm formation [20-23].

The aim of the study was to examine the properties of staphylococci, isolated from various objects (milk, pigs, companion animals, humans), their resistance to antibiotics, the ability to form a biofilm and the presence of genes, responsible for resistance to methicillin and biofilm formation.

\section{Materials and Methods}

This study was performed in the Ukrainian Laboratory of Quality and Safety of Agricultural Products of the National University of Life and Environmental Sciences of Ukraine (Kyiv, Ukraine) during 2019-2020.

This study used a total of 89 cultures of staphylococci (Table 1). Staphylococcus spp., isolated from milk, were kindly provided to us by the Uman Labs Milk Quality Laboratory (Uman, Cherkasy Region, Ukraine). Staphylococci, isolated from sick and clinically healthy companion animals, were collected at the Multivet Veterinary Clinic in Kyiv Region (Ukraine). Cultures, isolated from pigs, were collected from a pig farm in Kyiv Region. Strains, isolated from patients with purulent-inflammatory processes, were kindly provided to us by the Scientific Research Laboratory of the Shupik National Healthcare University of Ukraine (Kyiv, Ukraine). 
Table 1

Staphylococcal culture targets, used in this study

\begin{tabular}{ccccc}
\hline Type & Milk & Pigs & Companion animals & People \\
\hline Coagulase-positive (CoPS) & 2 & 3 & 2 & 11 \\
Coagulase-negative (CoNS) & 33 & 7 & 23 & 8
\end{tabular}

Antibiotic resistance of cultures was determined by the disc diffusion method (Kirby-Bauer) using antibiotic discs and a Müller-Hinton agar medium (HiMedia, India). The resistance of the obtained strains to Benzylpenicillin and Oxacillin was investigated. The results were evaluated in accordance with the recommendations of the European Committee for Antimicrobial Sensitivity EUCAST (version 10.0) [24] and the national criteria for the assessment of antibiotic resistance - the methodological guidance [25].

The ability to form biofilms in the derived isolates was determined and the results obtained were interpreted [26]. This study was performed using sterile polystyrene Petri dishes (Greiner Bio-One GmbH, Germany) of $d=100 \mathrm{~mm}$, which were added to $10 \mathrm{~mL}$ of Tryptone-soy broth (HiMedia, India) and added $1 \mathrm{ml}$ of inoculum with a cell content of 0.5 to MacFarland daily culture of studied Staphylococci. The plates were cultured in a thermostat at a temperature of $37^{\circ} \mathrm{C}$ for 24 hours, the residues of the nutrient medium were carefully removed, the planktonic forms were washed three times with a sterile phosphate buffer solution $\left(\mathrm{KH}_{2} \mathrm{PO}_{4} \cdot \mathrm{Na}_{2} \mathrm{PO}_{4} \cdot \mathrm{H}_{2} \mathrm{O}\right), \mathrm{pH}$ 7.2-7.4. The Petri dishes were air-dried and $10 \mathrm{~mL}$ of Ethanol $96 \%$ was added to fix the formed biofilms. The fixation exposure was 10 minutes. Then the fixing liquid was drained and after it, the Petri dishes were stained with $0.1 \%$ alcohol solution of crystal violet for $10 \mathrm{~min}$. Then washed the plates three times with a sterile phosphate buffer solution (pH 7.2) and dried. Contributed to $10 \mathrm{~mL}$ of Ethanol $96 \%$ and placed on a shaker for shaking for $30 \mathrm{~min}$. The contents of the Petri dishes were then pipetted and the amount of absorption of the biofilm of the dye was measured on an Evolution 300 spectrophotometer (Thermo Fisher Scientific, USA) at a wavelength of $570 \mathrm{~nm}$. The density of the formed biofilm was determined by measuring the adsorption level of the dye with ethanol measured in units of optical density (OD) using a spectrophotometer.

When the value of an optical density is less than 0.1 , it was considered that the strains do not form a biofilm, from 0.1 to 0.49 - the ability to form a film was considered as a low. When the value of optical density is from 0.5 to 1.0 - the medium density of the biofilm and the ability to form it. At values above 1.0 - the high ability to form a biofilm and its high density [26].

Polymerase Chain Reaction research. Studies of the obtained isolates for the presence of genes mecA, fem $\mathrm{B}$, ica $\mathrm{A}$, ica $\mathrm{D}$, and ica $\mathrm{AB}$ were performed by PCR with detection of results by separation in agarose gel. As a negative control, a mixture for PCR without DNA was used.

Genomic DNA from Staphylococcus spp culture was isolated by the express method. To do this, the lyophilized mass of the culture of Staphylococcus spp was dissolved in $1 \mathrm{~cm}^{3}$ of sterile buffered peptone water (HiMedia, India) and centrifuged at 13.5 thousand rpm for $2 \mathrm{~min}$, and the supernatant was removed. The bacterial pellet was resuspended in $200 \mathrm{~mm}^{3}$ of TE buffer and incubated in a thermostat at $95{ }^{\circ} \mathrm{C}$ for 5 minutes. Cell debris was precipitated by centrifugation at 5.0 thousand $\mathrm{rpm}$. for $2 \mathrm{~min}$ and took $180 \mathrm{~mm}^{3}$ of supernatant, which was used in PCR. The DNA concentration was measured on a Biofotomer spectrophotometer (Eppendorf, Germany) at a wavelength of $260 \mathrm{~nm}$. The amplification reaction was performed in a reaction mixture with a volume of $25 \mu \mathrm{l}$, with the following composition: 1x PCR buffer, $2.5 \mathrm{~mm} \mathrm{MgCl} 2,2.0 \mathrm{~mm}$ each of deoxynucleotide triphosphates, $10 \mathrm{pM}$ each of the primers for detection and 1 Unit. DNA polymerase. DNA was added in an amount of $5.0 \mathrm{~mm}^{3}(100-$ $150 \mathrm{ng}$ ). The studies were performed on a thermal cycler 2720 (Applied Biosystems, USA) with the temperature profile, given in the relevant literature source. The nucleotide sequences and other characteristics of the primers that were used in the study are given in (Table 2). The amplification products were separated in $1.5 \%$ agarose gel. 
Table 2

Characteristics of primers that were used in the studies

\begin{tabular}{|c|c|c|c|}
\hline Gene & Primer sequences & Product size (bp) & Reference \\
\hline mecA & $\begin{array}{l}\text { GTA GAA ATG ACT GAA CGT CCG ATA A } \\
\text { CCA ATT CCA CAT TGT TTC GGT CTA A }\end{array}$ & 310 & [11] \\
\hline $\mathrm{fem} B$ & $\begin{array}{l}\text { TTA CAG AGT TAA CTG TTA CC } \\
\text { ATA CAA ATC CAG CAC GCT CT }\end{array}$ & 651 & [11] \\
\hline$i c a A$ & $\begin{array}{l}\text { ACACTTGCTGGCGCAGTCAA } \\
\text { TCTGGAACCAACATCCAACA }\end{array}$ & 188 & {$[27]$} \\
\hline$i c a D$ & $\begin{array}{c}\text { ATGGTCAAGCCCAGACAGAG } \\
\text { AGTATTTTCAATGTTTAAAGCAA }\end{array}$ & 198 & [27] \\
\hline$i c a A B$ & $\begin{array}{l}\text { TTA TCA ATG CCG CAG TTG TC } \\
\text { GTT TAA CGC GAG TGC GCT AT }\end{array}$ & 546 & [28] \\
\hline
\end{tabular}

89 cultures of staphylococci were studied by polymerase chain reaction (Table 3 ).

Table 3

The number of staphylococci, tested for the presence of test genes, isolated from different objects

\begin{tabular}{|c|c|c|c|c|c|c|}
\hline \multirow{2}{*}{ Object } & \multirow{2}{*}{$\begin{array}{c}\text { Total } \\
\text { strains }\end{array}$} & \multicolumn{5}{|c|}{ The number of studied strains by type of genes } \\
\hline & & mecA & femB & icaA & icaD & icaAB \\
\hline Milk & 35 & 35 & 35 & 35 & 35 & 33 \\
\hline Pigs & 10 & 10 & 10 & 10 & 10 & 7 \\
\hline Companion animals & 25 & 25 & 25 & 25 & 25 & 23 \\
\hline People & 19 & 11 & 11 & 11 & 11 & 8 \\
\hline
\end{tabular}

Molecular genetic studies were performed to identify the presence of the following genes: mecA - responsible for resistance to methicillin; femB - encodes an enzyme, important for cross-linking of peptidoglycan; genes icaA, icaD, icaAB, which cause biofilm formation.

\section{Results}

Manifestation of phenotypic resistance to benzylpenicillin and oxacillin are shown in Table 4. Staphylococci, isolated from milk, were resistant to benzylpenicillin in $37.1 \%$ and oxacillin in $25.7 \%$ of cases. Among staphylococci, isolated from pigs, 3 coagulase-positive $(30 \%)$ and 1 coagulase-negative (10\%) strains were simultaneously resistant to benzylpenicillin and oxacillin. 10 coagulase-negative (40\%) and 1 coagulase-positive (4\%) staphylococci, isolated from companion animals, were resistant to benzylpenicillin and oxacillin. In the study of staphylococci, isolated from humans, it was found that $3(15.7 \%)$ coagulase-negative and 1 coagulase-positive $(5.2 \%)$ strains were simultaneously resistant to benzylpenicillin and oxacillin.

Table 4

Phenotypic antibiotic resistance of staphylococcal strains, isolated from different objects

\begin{tabular}{ccccccccc}
\hline \multirow{2}{*}{ Antibiotic } & \multicolumn{2}{c}{ Milk $\boldsymbol{n}=\mathbf{3 5}$} & \multicolumn{2}{c}{ Pigs $\boldsymbol{n}=\mathbf{1 0}$} & \multicolumn{2}{c}{ Companion animals $\boldsymbol{n}=\mathbf{2 5}$} & \multicolumn{2}{c}{ People $\boldsymbol{n}=\mathbf{1 9}$} \\
\cline { 2 - 9 } & CoPS & CoNS & CoPS & CoNS & CoPS & CoNS & CoPS & CoNS \\
\hline Benzylpenicillin & $2(5.7 \%)$ & $11(31.4 \%)$ & $3(30 \%)$ & $1(10 \%)$ & $2(8.0 \%)$ & $10(40.0 \%)$ & $8(42.1 \%)$ & $8(42.1 \%)$ \\
Oxacillin & $1(2.8 \%)$ & $8(22.8 \%)$ & $3(30 \%)$ & $1(10 \%)$ & $1(4.0 \%)$ & $10(40.0 \%)$ & $1(5.2 \%)$ & $3(15.7 \%)$
\end{tabular}

The results of detection of pathogenicity genes in staphylococcal cultures by polymerase chain reaction are shown in Table $\mathbf{5}$. 
Table 5

Detection of genes that cause the phenomenon of biofilm formation and polyresistance to antibiotics by PCR

\begin{tabular}{|c|c|c|c|c|c|c|c|c|}
\hline \multirow{2}{*}{ Gene } & \multicolumn{2}{|c|}{ Milk $n=35$} & \multicolumn{2}{|c|}{ Pigs $n=10$} & \multicolumn{2}{|c|}{ Companion animals $n=25$} & \multicolumn{2}{|c|}{ People $n=19$} \\
\hline & CoPS & CoNS & CoPS & CoNS & CoPS & CoNS & CoPS & CoNS \\
\hline mecA & $1(2.8 \%)$ & 0 & $1(10.0 \%)$ & $1(10.0 \%)$ & 0 & 0 & $1(5.2 \%)$ & $3(15.7 \%)$ \\
\hline femB & $1(2.8 \%)$ & 0 & $1(10.0 \%)$ & 0 & 0 & 0 & 0 & 0 \\
\hline icaA & $2(5.7 \%)$ & 0 & $1(10.0 \%)$ & 0 & $1(4.0 \%)$ & 0 & $6(31.5 \%)$ & 0 \\
\hline icaD & $2(5.7 \%)$ & $3(8.5 \%)$ & $1(10.0 \%)$ & 0 & 0 & $3(12.0 \%)$ & $8(42.1 \%)$ & $4(21.0 \%)$ \\
\hline icaAB & 0 & $2(5.7 \%)$ & 0 & 0 & 0 & 0 & 0 & $3(15.7 \%)$ \\
\hline
\end{tabular}

In particular, in 1 strain of coagulase-positive staphylococcus, isolated from milk, simultaneous phenotypic resistance to oxacillin and benzylpenicillin was established and the presence of mecA and femB genes was detected, which was confirmed by polymerase chain reaction.

Staphylococci, isolated from milk, formed a biofilm of high $(20.0 \%)$, medium $(34.3 \%)$ and low $(28.7 \%$ ) density. Genes, which determine the formation of the biofilm, were found in 7 studied strains. In particular, icaD and isaA were detected simultaneously in 2 coagulase-positive strains, and the icaD gene was also detected in 3 coagulase-negative strains, isolated from milk.

Among staphylococci, isolated from pigs, the presence of mecA and femB genes was detected in $1(10 \%)$ coagulase-positive staphylococcus. The mecA gene was also present in 1 coagulase-negative staphylococcus, isolated from pigs.

In $100 \%$ of cases, staphylococci, isolated from pigs, showed the ability to biofilm formation. In particular, a high-density biofilm, formed by $10 \%$ of staphylococci, $90 \%$ formed a medium-density biofilm. At the same time, the presence of genes, responsible for the formation of the biofilm (icaD, isaA), were detected only in 1 (10\%) of coagulase-positive staphylococcus.

Staphylococci, isolated from companion animals, that showed phenotypic resistance to benzylpenicillin and oxacillin, did not contain the structural genes mecA and femB. $88 \%$ of the studied strains showed the ability to form a high-density biofilm, the remaining $12 \%$ formed medium-density biofilms. The icaD biofilm gene was found in $3(12.0 \%)$ coagulase-negative staphylococci, and the icaA biofilm gene was isolated in 1 (4\%) coagulase-positive staphylococcus.

Staphylococci, isolated from humans, shows that $3(15.7 \%)$ coagulase-negative and 1 coagulase-positive (5.2\%) strains possessed the structural genome mecA. Also 1 coagulase-positive (5.2\%) strain had both structural genes mecA and femB (5.2\%). Among this group of strains, high-density biofilms were able to form $68.4 \%$, and medium-density biofilms $-31.6 \%$. Simultaneously, 6 coagulase-positive staphylococci contained genes for the formation of biofilm icaD and icaA. Genes D2 were present in 2 coagulase-positive and 4 (21.0\%) coagulase-negative staphylococci. The biofilm gene isaAB was isolated from 3 (15.7\%) coagulase-negative strains of staphylococci, isolated from humans.

\section{Discussion}

In this study we used 89 strains, of which 18 (20.2\%) were coagulase-positive. 2 strains of coagulase-positive staphylococci, isolated from different animals and humans, had a complete set of phenotypic (plasma coagulation, biofilm formation, resistance to oxacillin and benzylpenicillin) and genotypic (mecA, femB, icaA, icaD).

Coagulase-negative staphylococci, isolated from various animals and humans, were resistant to oxacillin, benzylpenicillin (according to EUCAST [24] and Guidelines for [25], and had the ability to form biofilms with mecA, icaAB, icaD in their structure in $3.3 \%$ of cases.

Staphylococci, isolated from different animals and humans, were able to form a biofilm and had the appropriate set of genes (icaD, icaAB) in $5.6 \%$ of cases.

The data, obtained by us, are consistent with the publications [26, 29, 30], that $S$. aureus, isolated from various samples of raw materials and products of animal origin [29], milk and washes from milking equipment forms biofilms of high density [26] and has polyresistance to various antibiotics, and has the presence of mecA [30]. 
Thus, according to [31], the average level of pathogenic staphylococci, accompanied by their significant polyresistance in pigs in Ukraine for the period 2013-2018 was $1.3 \%$.

The obtained results indicate that the studied strains of staphylococci, regardless of the source of isolation, were phenotypically resistant to oxacillin in $31.4 \%$ of cases and formed biofilms in $100 \%$ of cases.

The analysis of the obtained data gives grounds to believe that staphylococci, regardless of the source of isolation, may be carriers of genetic determinants of pathogenicity, in particular genes that cause resistance to methicillin (mec) and biofilm formation (femB, icaA, icaD).

However, according to the obtained data, the strains, isolated from the hospital patients with nosocomial staphylococcus, had the highest pathogenic potential.

The studied strains of staphylococci have a rich variety of pathogenic properties and are represented by both coagulase-positive and coagulase-negative representatives. The vast majority of studied staphylococci have certain pathogenic symptoms depending on the object of excretion. Staphylococci, isolated from animals, were almost at the level with staphylococci, isolated from humans, by pathogenic properties and, in some aspects, even exceeded.

At the same time, it should be noted, that the phenotypic manifestation of resistance to oxacillin, as well as the ability to form biofilms, in our studies, did not coincide with the results of the detection of relevant genetic markers. Indirectly, this fact indicates the need for in-depth study of this phenomenon in order to identify previously unknown genetic loci that cause the phenotypic manifestation of resistance and the ability to form biofilms, which is important for understanding the pathogenesis of diseases, caused by staphylococci and their timely diagnosis.

These studies have some limitations. Namely, a small number of staphylococcal isolates studied. Also, financial constraints did not allow DNA sequencing of isolated staphylococci and comparative analysis of DNA nucleotide sequences with NCBI data and other databases of DNA nucleotide sequences.

The prospect of further research is to identify previously unknown genetic loci that cause the phenotypic manifestation of resistance and the ability to form biofilms, which is important for understanding the pathogenesis of diseases, caused by staphylococci and their timely diagnosis. To this end, it is advisable to create a collection of isolates of staphylococci, characterized by resistance to antibiotics and the formation of a biofilm, and to sequence their DNA.

\section{Conclusion}

The studied strains of staphylococci, regardless of the source of isolation, were phenotypically resistant to oxacillin in $31.4 \%$ of cases and formed biofilms in $100 \%$ of cases.

Coagulase-negative staphylococci, isolated from various animals and humans, were resistant to oxacillin, benzylpenicillin, had the ability to form biofilms and had in their structure the genes mecA, icaAB, icaD in $3.3 \%$ of cases.

Staphylococci, regardless of the source of isolation, both coagulase-positive and coagulase-negative, can be carriers of genetic determinants of pathogenicity, in particular genes that cause resistance to methicillin (mec) and biofilm formation (femB, icaA, icaD).

\section{References}

[1] Vitale, M., Galluzzo, P., Buffa, P. G., Carlino, E., Spezia, O., Alduina, R. (2019). Comparison of Antibiotic Resistance Profile and Biofilm Production of Staphylococcus aureus Isolates Derived from Human Specimens and Animal-Derived Samples. Antibiotics, 8 (3), 97. doi: http://doi.org/10.3390/antibiotics8030097

[2] Adame-Gómez, R., Castro-Alarcón, N., Vences-Velázquez, A., Toribio-Jiménez, J., Pérez-Valdespino, A., Leyva-Vázquez, M.-A., Ramírez-Peralta, A. (2020). Genetic Diversity and Virulence Factors of S. aureus Isolated from Food, Humans, and Animals. International Journal of Microbiology, 2020, 1-10. doi: http://doi.org/10.1155/2020/1048097

[3] Diekema, D. J., Pfaller, M. A., Shortridge, D., Zervos, M., Jones, R. N. (2019). Twenty-Year Trends in Antimicrobial Susceptibilities Among Staphylococcus aureus From the SENTRY Antimicrobial Surveillance Program. Open Forum Infectious Diseases, 6 (Supplement_1), S47-S53. doi: http://doi.org/10.1093/ofid/ofy270 
[4] Heilmann, C., Ziebuhr, W., Becker, K. (2019). Are coagulase-negative staphylococci virulent? Clinical Microbiology and Infection, 25 (9), 1071-1080. doi: http://doi.org/10.1016/j.cmi.2018.11.012

[5] Otto, M. (2012). Coagulase-negative staphylococci as reservoirs of genes facilitating MRSA infection. BioEssays, 35 (1), 4-11. doi: http://doi.org/10.1002/bies.201200112

[6] Haag, A. F., Fitzgerald, J. R., Penadés, J. R. (2019). Staphylococcus aureus in Animals. Microbiology Spectrum, 7 (3). doi: http://doi.org/10.1128/microbiolspec.gpp3-0060-2019

[7] Loncaric, I., Tichy, A., Handler, S., Szostak, M., Tickert, M., Diab-Elschahawi, M. et. al. (2019). Prevalence of Methicillin-Resistant Staphylococcus sp. (MRS) in Different Companion Animals and Determination of Risk Factors for Colonization with MRS. Antibiotics, 8 (2), 36. doi: http://doi.org/10.3390/antibiotics8020036

[8] Kozytska, T., Garkavenko, T. (2019). Circulation of Methicillin-resistant Staphylococcus (MRS) in Livestock and Domestic Animals. Proceedings of the BTRP Ukraine Regional One Health Research Symposium. Available from: https:/labukraineblog.files.wordpress.com/2019/05/2019-swmp-symposium-program-final-lowres.pdf

[9] Lozano, C., Gharsa, H., Ben Slama, K., Zarazaga, M., Torres, C. (2016). Staphylococcus aureus in Animals and Food: Methicillin Resistance, Prevalence and Population Structure. A Review in the African Continent. Microorganisms, 4 (1), 12. doi: http://doi.org/10.3390/microorganisms4010012

[10] Bergerbachi, B., Tschierske, M. (1998). Role of fem factors in methicillin resistance. Drug Resistance Updates, 1 (5), $325-335$. doi: http://doi.org/10.1016/s1368-7646(98)80048-4

[11] Jonas, D., Speck, M., Daschner, F. D., Grundmann, H. (2002). Rapid PCR-Based Identification of Methicillin-Resistant Staphylococcus aureus from Screening Swabs. Journal of Clinical Microbiology, 40 (5), 1821-1823. doi: http://doi.org/10.1128/ jcm.40.5.1821-1823.2002

[12] Gómez-Sanz, E., Ceballos, S., Ruiz-Ripa, L., Zarazaga, M., Torres, C. (2019). Clonally Diverse Methicillin and Multidrug Resistant Coagulase Negative Staphylococci Are Ubiquitous and Pose Transfer Ability Between Pets and Their Owners. Frontiers in Microbiology, 10. doi: http://doi.org/10.3389/fmicb.2019.00485

[13] Kaspar, U., von Lützau, A., Schlattmann, A., Roesler, U., Köck, R., Becker, K. (2018). Zoonotic multidrug-resistant microorganisms among small companion animals in Germany. PLOS ONE, 13 (12), e0208364. doi: http://doi.org/10.1371/ journal.pone.0208364

[14] Palma, E., Tilocca, B., Roncada, P. (2020). Antimicrobial Resistance in Veterinary Medicine: An Overview. International Journal of Molecular Sciences, 21 (6), 1914. doi: http://doi.org/10.3390/ijms21061914

[15] Diekema, D. J., Pfaller, M. A., Shortridge, D., Zervos, M., Jones, R. N. (2019). Twenty-Year Trends in Antimicrobial Susceptibilities Among Staphylococcus aureus From the SENTRY Antimicrobial Surveillance Program. Open Forum Infectious Diseases, 6 (Supplement_1), S47-S53. doi: http://doi.org/10.1093/ofid/ofy270

[16] Vishovan, J., Ushkalov, V. (2018). Spread of staphylococcus and diseases caused by them. Visnyk Agrarnoi Nauky, 96 (2), 36-42. doi: http://doi.org/10.31073/agrovisnyk201802-06

[17] Vishovan, Y., Ushkalov, V., Kepple, O., Granate, A. (2020). Antimicrobial resistance and biological properties of Staphylococci isolated from pigs. One Health \& Risk Management, 1 (1), 58-63. doi: http://doi.org/10.38045/ohrm.2020.1.09

[18] Vishovan, Y., Ushkalov, V., Vygovska, L., Machuskyy, O., Hranat, A., Shaiko, A., Boianovskiy, S. (2020). Biological properties of staphylococci derived from cats and dogs. Ukrainian Journal of Veterinary Sciences, 11 (3), 56-64. doi: http://doi.org/ 10.31548/ujvs2020.03.006

[19] CDC. Antibiotic Resistance Threats in the United States (2019). Atlanta: U.S. Department of Health and Human Services, CDC. doi: http://dx.doi.org/10.15620/cdc:82532

[20] Ahmadrajabi, R., Layegh-Khavidaki, S., Kalantar-Neyestanaki, D., Fasihi, Y. (2017). Molecular analysis of immune evasion cluster (IEC) genes and intercellular adhesion gene cluster (ICA) among methicillin-resistant and methicillin-sensitive isolates of Staphylococcus aureus. Journal of preventive medicine and hygiene, 58 (4), E308-E314. doi: http://doi.org/10.15167/2421-4248/ jpmh2017.58.4.711

[21] Arciola, C. R., Campoccia, D., Ravaioli, S., Montanaro, L. (2015). Polysaccharide intercellular adhesin in biofilm: structural and regulatory aspects. Frontiers in Cellular and Infection Microbiology, 5. doi: http://doi.org/10.3389/fcimb.2015.00007

[22] Otto, M. (2018). Staphylococcal Biofilms. Microbiology Spectrum, 6 (4). doi: http://doi.org/10.1128/microbiolspec.gpp3-0023-2018

[23] Paharik, A. E., Horswill, A. R. (2016). The Staphylococcal Biofilm: Adhesins, Regulation, and Host Response. Microbiology Spectrum, 4 (2). doi: http://doi.org/10.1128/microbiolspec.vmbf-0022-2015

[24] Eucast. The european committee on antimicrobial susceptibility testing (2020). Available at: http://www.eucast.org/

[25] Determination of susceptibility of microorganisms to antibacterial drugs (2007). Law of Ministry of health of Ukraine No. 167. 05.04.2007. Available at: https://zakon.rada.gov.ua/rada/show/v0167282-07 
[26] Kukhtyn, M., Krushelnytska, N. (2014). Forming of biofilms of microorganisms obtained from milking equipment. The Animal Biology, 16 (1), 95-103.

[27] Szweda, P., Schielmann, M., Milewski, S., Frankowska, A., Jakubczak, A. (2012). Biofilm production and Presence of ica and bap Genes in Staphylococcus aureus Strains Isolated from Cows with Mastitis in the Eastern Poland. Polish Journal of Microbiology, 61 (1), 65-69. doi: http://doi.org/10.33073/pjm-2012-009

[28] Frebourg, N. B., Lefebvre, S., Baert, S., Lemeland, J. F. (2000). PCR-Based assay for discrimination between invasive and contaminating Staphylococcus epidermidis strains. Journal of clinical microbiology, 38 (2), 877-880. doi: http://doi.org/10.1128/ jcm.38.2.877-880.2000

[29] Garkavenko, T. O., Gorbatyuk, O. I., Kozytska, T. G., Andriyashchuk, V. O., Kukhtin, D. M., Kovalenko, V. L. et. al. (2020). Study of the ability of S. aureus field isolates selected from raw materials and livestock products to form biofilms. Bulletin "Veterinary Biotechnology", 37, 20-30. doi: http://doi.org/10.31073/vet_biotech37-02

[30] Berhilevych, O. M., Kasianchuk, V. V., Kukhtyn, M. D., Lotskin, I. M., Garkavenko, T. O., Shubin, P. A. (2017). Characteristics of antibiotic sensitivity of Staphylococcus aureus isolated from dairy farms in Ukraine. Regulatory Mechanisms in Biosystems, 8 (4), 559-563. doi: http://doi.org/10.15421/021786

[31] Gorbatyuk, O. I., Garkavenko, T. O., Kozytska, T. G., Ordinska, D. O., Musiec, I. V., Schur, N. V. (2019). Bacteriological monitoring of staphylococcal infection in pigs, pork and ready-to-eat products from pork in Ukraine, biological risks for human. Scientific and Technical Bulletin of State Scientific Research Control Institute of Veterinary Medical Products and Fodder Additives and Institute of Animal Biology, 20 (2), 194-200. doi: http://doi.org/10.36359/scivp.2019-20-2.25

How to cite: Vishovan, Y., Ushkalov, V., Vygovska, L., Ishchenko L., Salmanov A., Bilan A., Kalakailo L., Hranat A., Boianovskiy, S. (2021). Biofilm formation and antibiotic resistance in staphylococcus isolated from different objects. EUREKA: Life Sciences, 4, $58-65$. doi: https://doi.org/10.21303/2504-5695.2021.001925 